\title{
DAS PROPOSIÇÕES DO ESTÁGIO SUPERVISIONADO AOS DESAFIOS DA PRÁTICA: A FORMAÇÃO INICIAL DE PROFESSORES-ESTUDANTES NA PEDAGOGIA DO PARFOR
}

\author{
FROM SUPERVISED TEACHING PRACTICUM PROPOSITIONS TO THE \\ CHALLENGES OF PRACTICE: INITIAL EDUCATION OF STUDENT-TEACHERS \\ IN THE PARFOR PEDAGOGY
}

Maria de Fátima Barbosa Abdalla*

\begin{abstract}
Resumo: Este texto pretende, fundamentando-se em Bourdieu (1997) e Freire (1997), examinar quais proposições e desafios estão sendo vivenciados por professores-estudantes na Pedagogia do PARFOR, em relação ao contexto de trabalho e às práticas profissionais de início de carreira. Trata-se de uma pesquisa longitudinal, realizada em três etapas: aplicação de questionário para 43 professores; grupo focal com oito professoras; e três entrevistas semiestruturadas. A partir das proposições do estágio, a análise foi desenvolvida em duas dimensões: $1^{\text {a }}$ político-normativa: trata das formas de regulação do PARFOR e do estágio; $2^{\mathrm{a}}$ epistemológico-metodológica: apresenta concepções do estágio, que têm na relação teoria-prática um elemento fundante. Entre os desafios da prática e as proposições do contexto de formação, os resultados indicam a necessidade de $1^{\circ}$ no campo do estágio: integrá-lo com as demais disciplinas; articular a instituição formadora e escolas-campo; valorizar o estágio como campo de conhecimento; e assumir uma nova postura frente a ele, fortalecendo a relação teoria-prática; e $2^{\circ}$ no contexto de trabalho: considerar que o projeto de estágio seja planejado e avaliado pela instituição formadora e escolas; desenvolver uma postura metodológica/epistemológica frente ao estágio para produzir conhecimentos; considerá-lo como projeto de formação; $3^{\circ}$ nas práticas profissionais: analisar as "disposições legais" como "formas de regulação"; ressignificar o estágio e a profissão docente; identificar os problemas-chave relativos à sala de aula, para intervir com maior conscientização; e pensar na atividade docente, tendo como pressupostos a transmissão e a co-construção de conhecimento com base no diálogo entre a teoria e a prática.
\end{abstract}

Palavras-chave: Estágio supervisionado. Professores iniciantes. PARFOR. Práticas profissionais.

Abstract: Based on Bourdieu (1997) and Freire (1997) this text intends to examine the propositions and challenges teacher-students experience in the PARFOR pedagogy in relation to both the workplace, and the professional practices in their early years into teaching. It is a longitudinal survey carried out in three stages: application of a questionnaire to 43 teachers, focus group discussions with 8 teachers, and 3 semi-structured interviews. From the teaching practicum propositions, the analysis was performed at two dimensions: 1st political and normative, addressing PARFOR and the teaching practicum regulation; and 2nd epistemological and methodological, presenting conceptions about teaching practicum that consider theory-practice a foundational element. Among the challenges of practice, and the propositions in the training context, the results point to the need for: 1st in the teaching practicum field: its integration with other disciplines; the articulation between the institution providing the training and the field schools; the valuing of the teaching practicum as a field of knowledge; the need for taking a new stance towards the teaching practicum which

\footnotetext{
* Doutora em educação pela USP. Professora do Programa de Pós-Graduação da Universidade Católica de Santos. E-mail: <mfabdalla@uol.com.br>.

* Doctor in Education from USP. Professor at the Post Graduate Programme from the Santos Catholic University. E-mail: <mfabdalla@uol.com.br>.
} 
strengthens the relationship between theory and practice; 2nd in the work context: planning and assessing the teaching practicum project by the institution providing the training and schools; the development of a methodological/epistemological approach to the teaching practicum in order to produce knowledge; the need to consider the teaching practicum as a training project; 3rd in the professional practices: the need to analyze the "legal provisions" as "forms of regulation"; the need to bring new meaning to the teaching practicum, and to the teaching profession; the need to identify the key issues related to the classroom to intervene with greater awareness; and the need to think about the teaching activity using conveying and co-constructing knowledge based on the dialogue between theory and practice.

Keywords: Supervised internship. Beginning teachers. PARFOR. Professional practices.

\section{Introdução}

A crítica epistemológica não se dá sem uma crítica social. (BOURDIEU, 1994, p. 7).

As primeiras inquietações referentes a este trabalho surgiram por conta de se pensar os desafios da prática que vivenciam os professores-estudantes do curso de Pedagogia do PARFOR - Programa instituído a partir de uma Política Nacional de Formação de Profissionais do Magistério da Educação Básica (BRASIL, 2009) - em seus primeiros anos de profissão. Trata-se do curso de Pedagogia/PARFOR, desenvolvido, desde o segundo semestre de 2010, por uma universidade comunitária e confessional da Baixada Santista/SP. Ao lado disso, era preciso refletir, também, sobre quais seriam as contribuições da formação inicial deste programa no sentido de minimizar o "choque com a realidade” destes professores, como já havia apontado Silva (1997, p. 54-60), referindo-se ao termo criado por Simon Veenman (1984).

O cenário dos primeiros anos de profissão tem sido pauta de diversas pesquisas, que têm, também, desenvolvido enfoques diferentes. Por exemplo, Silva (1997) revela que o interesse por este período de carreira dos professores iniciantes está centrado na importância da informação que é coletada a fim de redefinir programas, tanto em relação à formação inicial, quanto à formação contínua, de sorte a "minorar as dificuldades com que se confrontam os recém-formados quando iniciam sua atividade profissional” (p. 56).

Marcelo García (1999), ao tratar da formação de professores principiantes, destaca que este período de iniciação profissional dos professores é “o período de tempo que abarca os primeiros anos, nos quais os professores fazem a transição de estudantes para professores” (p. 113). Considera, também, que este é um momento de "tensões e aprendizagens intensivas" frente a contextos desconhecidos, em que estes professores "devem adquirir conhecimento profissional”, além de um “certo equilíbrio pessoal” (p. 113). Aponta, como resultados de suas pesquisas, que estes professores principiantes: a) preocupam-se com o seu aperfeiçoamento; b) assumem que a sua formação é incompleta; c) revelam que os primeiros anos de ensino são difíceis, pessoal e profissionalmente; d) destacam que as experiências como estudantes influenciam em parte suas decisões; e) e anunciam que seus maiores problemas se referem mais aos aspectos didáticos do que a problemas pessoais ou organizacionais (p. 113).

Ainda, Marcelo García (1999, p. 118119), ao citar Zimpher (1988), indica mais alguns problemas em relação a este período de iniciação, dos quais destacamos os que 
seguem: a) a forma como se dá a incorporação na escola dos professores iniciantes, pois, muitas vezes, cabe a eles enfrentar as situações mais difíceis e conflitantes no que diz respeito, por exemplo, à gestão de sala de aula; b) a falta de apoio de professores mais experientes e/ou da coordenação; c) as expectativas que a instituição tem a respeito destes professores, que são as mesmas para os professores mais experientes; e d) os momentos de estresse ou mesmo de evasão destes professores da sala de aula, por todos os motivos apontados anteriormente.

Outras autoras, como Cunha e Zanchet (2010, p. 190-193), ao analisar os dados referentes às tendências de 201 pesquisas sobre a inserção profissional dos professores iniciantes, destacam como temáticas: a) as experiências de acompanhamento $e$ formação dos iniciantes - anunciando a importância de se compreender que o processo de inserção profissional não é "responsabilidade individual", mas um "desafio institucional e de políticas públicas" (p. 191); b) a construção dos saberes dos professores iniciantes - identificando que os professores iniciantes se instituem a partir de uma "perspectiva conteudista" (p. 191), e que logo percebem que os saberes exigem uma "inserção mais intensa na prática" (p. 191); c) os saberes de professores/alunos na formação inicial/estágios - evidenciando que as propostas de formação inicial vivem uma permanente "tensão entre os polos da teoria e da prática e do ensino e da pesquisa" (p. 191); d) a inserção profissional, as políticas públicas e o trabalho docente - abordando as condições de trabalho, as políticas públicas e ressignificando o trabalho docente; e) os professores principiantes em contexto desfavoráveis - denunciando a falta de condições de trabalho destes professores e apontando para o alto "abandono da profissão" (p. 192); f) os professores iniciantes frente à educação digital - indicando a importância de se renovar as práticas de ensino e de aprender que ainda seguem "padrões tradicionais" (p. 193); g) a formação de formadores dos iniciantes - abordando a necessidade de que este processo de iniciação seja de "acompanhamento reflexivo e colaborativo" (p. 193); e h) a iniciação à docência $e$ à pesquisa - explorando "metodologias investigativas como favorecedoras de processos de intervenção na educação dos professores iniciantes” (p. 193).

Diante dessas temáticas diferenciadas, levamos em consideração, na pesquisa que desenvolvemos, analisar alguns aspectos não só da formação inicial dos professores-estudantes da Pedagogia/PARFOR, como também do campo de estágio, tendo em vista a articulação do contexto de formação com o de trabalho, problematizando, na medida do possível, as práticas profissionais destes professores iniciantes.

Com efeito, quando se toma a direção de se escrever sobre a formação inicial de professores e, em especial, daqueles que já estão no início de carreira, têm-se, no mínimo, duas preocupações. A primeira diz respeito a olhar para o contexto de formação alinhavado com o contexto da prática destes professores-estudantes e refletir se eles estão compreendendo este universo de "inovações" que os circula, a partir até do Decreto 6755/09 (BRASIL, 2009), que possibilitou que estes sujeitos pudessem frequentar o curso de Pedagogia. Pensar nesta questão, em particular, demanda intenções pedagógicas, especialmente, por parte dos professores formadores, no sentido de possibilitar que os professores-estudantes, sobretudo, nos primeiros anos da profissão, possam ter acesso a um conhecimento que redirecione seus olhares para analisar e interpretar as situações de trabalho e o seu senso prático de ser e estar na profissão professor (ABDALLA, 2006). 
E a segunda preocupação tem a ver com a possibilidade de se levantar uma série de aspectos, com base na vivência deste alunado e das experiências apresentadas. Esses aspectos devem vir a contribuir para a sua formação e desenvolvimento profissional, assim como para a reorganização de estratégias e a transformação de suas crenças, a fim de que encontrem caminhos para superar os desafios da escola e da sala de aula.

Com base nestas colocações preliminares, este texto objetiva examinar, então, quais proposições e desafios estão sendo vivenciados por professores-estudantes do curso de Pedagogia/PARFOR (BRASIL, 2009), em relação ao contexto de trabalho e às práticas profissionais de início de carreira, tendo em vista o campo do estágio.

Sob essa ótica, delineamos, primeiro, três desafios, que passam pela opção teóricometodológica, pelo embate teórico sobre o estágio e pelo que propõe o PARFOR. Em um segundo momento, contextualizamos a pesquisa, situando as etapas, o campo e seus sujeitos, as opções teórico-metodológicas e as dimensões de análise. E, por fim, refletimos sobre as implicações do PARFOR no estágio, no contexto de trabalho e nas práticas profissionais destes professoresestudantes, destacando o significado da relação teoria-prática para estes professores iniciantes.

Como pano de fundo, este estudo reforça o pensamento de Bourdieu (1994, p. 7), registrado na epígrafe inicial, na medida em que aponta (e nos convence) que "a crítica epistemológica”, observada em diversos momentos de formação de professores-estudantes no curso de Pedagogia/ PARFOR e no acompanhamento do estágio, "não se dá sem uma crítica social”. Mas este trabalho também se fundamenta em Freire (1997), na medida em que, junto com ele, acreditamos que "há uma pedagogicidade indiscutível na materialidade do espaço” (p. 50). O que supõe a necessidade destes professores tomarem consciência de se voltarem para a própria prática como elemento essencial para construir criticamente as suas próprias realidades.

\section{Do PARFOR: entrelaçando desafios e proposições}

Aquilo a que se chama a "ruptura epistemológica”, quer dizer, o pôr-em-suspenso as pré-construções vulgares e os princípios geralmente aplicados na realização dessas construções, implica uma ruptura com modos de pensamento, conceitos, métodos que têm a seu favor todas as aparências do senso comum (grifos do autor), do bom senso vulgar e do bom senso científico... (BOURDIEU, 1998c, p. 49).

Para compreender mais de perto o movimento do PARFOR, pretendendo fazer uma primeira "ruptura epistemológica", de acordo com as palavras de Bourdieu (1998c, p. 49), levantamos as seguintes questões: o que vem a ser, então, a Política Nacional de Formação de Profissionais do Magistério da Educação Básica/PARFOR? E, se considerarmos mais de perto o campo do estágio e o contexto de trabalho, na implementação do PARFOR, quais seriam os aspectos delineados por esta política que poderiam ser considerados como desafios e/ou proposições?

De imediato, reconhecemos que estas não são questões fáceis, mas nos colocam, como diria Bourdieu (1997, p. 202), em uma "lógica", que "não é a da condenação ou da denúncia política”, e sim a da "interrogação epistemológica”, porque “dirigida à própria postura epistêmica, aos pressupostos inscritos no fato de retirar-se do mundo e da ação no mundo para pensá-los”. Seguindo nesta direção, trataremos, aqui, de desvelar os desafios e proposições postos no percurso da pesquisa. 


\section{- O $1^{0}$ desafio: a opção teórico- metodológica como proposição de análise}

\begin{abstract}
Compreender a gênese social de um campo, e apreender aquilo que faz a necessidade específica da crença que o sustenta, do jogo de linguagem que nele se joga, das coisas materiais e simbólicas em jogo que nele se joga, das coisas materiais e simbólicas em jogo que nele se geram... (BOURDIEU, 1998c, p. 48).
\end{abstract}

Fundamentamo-nos na filosofia de ação de Bourdieu (1997, 1998a, 1998b), pois necessitávamos refletir sobre o PARFOR como espaço social de formação de professores. Ao mesmo tempo, a nossa intenção era pensar, de modo mais intenso, nas implicações deste Programa na formação dos 43 professores-estudantes da Pedagogia do PARFOR, no que diz respeito ao campo do estágio, ao contexto de trabalho e às práticas profissionais a serem desenvolvidas por estes sujeitos nos primeiros anos da profissão docente. E, ainda, como diria o autor (1998c, p. 69), "apreender aquilo que faz a necessidade específica da crença que o sustenta, do jogo de linguagem que nele se joga, das coisas materiais e simbólicas em jogo que nele se geram".

$\mathrm{O}$ que se quer, aqui, é fazer, segundo Bourdieu (1997), uma leitura adequada da análise da relação entre as posições sociais (conceito relacional), as disposições (ou o habitus) e as tomadas de posição, ou seja, as "escolhas" que estes professores-estudantes fazem, tendo em vista seu contexto de formação e de trabalho. Recordando, para isso, que um princípio fundamental da filosofia de ação, em Bourdieu (1997, 1998a,1998b), é apreender as coisas em relação. Segundo ele (1998b, p. 31), o real é relacional e é preciso pensar relacionalmente (p. 28). Ou seja, pensar em um espaço social, em que os agentes ou os grupos são distribuídos em função de sua posição, formado por estruturas objetivas, a que o autor dá o nome de campos sociais, e estruturas incorporadas, ou seja, o habitus. Conforme Bourdieu (1998a), o habitus poderia ser definido como "o sistema dos esquemas interiorizados que permitem engendrar todos os pensamentos, percepções e as ações características de uma cultura” (p. 349).

Mas como é possível fazer a leitura sistemática do real de tal modo que a interpretação tenha algum sentido? Pensamos, em concordância com o autor, que é preciso compreender a lógica específica das práticas: o princípio da realidade. Princípio este que orienta a relação entre as posições dos agentes e as disposições, traduzidas, por Bourdieu (1997, p. 208), como princípio da disposição ou habitus, que, como o próprio autor afirma, "guia a ação à maneira de uma necessidade lógica”. É, portanto, através das disposições dos agentes que se realizam as potencialidades, inscritas nas posições.

A confrontação entre as posições e as disposições, entre o esforço para construir o "posto" e a necessidade de se habituar ao "posto" (BOURDIEU, 1996, p. 303), e as decorrentes tomadas de posição vão vivificando o princípio da realidade. Pensar neste princípio é também refletir sobre dois outros: o da pertinência e o da ação histórica. Na medida em que estamos sendo orientados pelo princípio da pertinência (BOURDIEU, 1994, p. 43), assumimos uma forma particular de relação com a realidade.

O princípio de pertinência ou de pertença à realidade permite que estejamos nos inscrevendo em um campo determinado, para constituí-lo, ocupando, assim, uma posição na estrutura da distribuição do capital simbólico específico e dispondo de uma parte de autonomia para ser possível tomar algumas decisões. 
Pertencer a um grupo também é encarnar um pouco do mundo social, fruto da ação histórica. Aí se configura, então, o princípio da ação histórica. Como afirma Bourdieu (1994, p. 40-41):

Ele não reside nem na consciência, nem nas coisas, mas na relação entre dois estados do social, ou seja, entre a História objetivada nas coisas, na forma de instituições, e a História encarnada nos corpos, sob a forma desses sistemas de disposições duráveis,

que o autor chama de habitus. E, neste sentido, ainda é preciso compreender que "o corpo está dentro do mundo social, mas o mundo social está dentro do corpo” (p. 41).

Com efeito, os princípios aqui enunciados - relacional, da realidade, da disposição ou habitus, da pertinência ou pertença, da ação histórica -, encadeados didaticamente, tiveram a pretensão, ainda que incipiente, de pensar a teoria de ação proposta por Bourdieu. Além disso, pensá-la, tendo como ponto central nortear a análise que faremos a respeito da formação e das práticas profissionais dos professores-estudantes, tendo em vista o campo do estágio e as práticas desenvolvidas no início de carreira.

Estes princípios orientadores fazem-nos lembrar, ainda, de alguns conceitos nucleares da teoria freireana (1997), tais como: a conscientização, o que implica, necessariamente, o compromisso do sujeito com a transformação de sua realidade; a disponibilidade para o diálogo, no sentido de viabilizar a "experiência da abertura como experiência fundante do ser inacabado" (p. 153); e a capacidade de intervir no mundo, de transformá-lo, pois como diria o autor: "no mundo da História, da cultura, da política, constato não para me adaptar, mas para mudar" (FREIRE, 1997, p. 85-86). E, nesta direção, seria necessário, para melhor escla- recer o campo do estágio a ser desenvolvido na Pedagogia do PARFOR, alertar estes estudantes sobre o embate teórico, indicando as dificuldades e as proposições para este campo.

\section{- $O 2^{\circ}$ desafio: compreender o embate teórico sobre o estágio (dificuldades e proposições)}

A reflexão crítica sobre a prática se torna uma exigência da relação Teoria/Prática sem a qual a teoria pode ir virando blablablá e a prática, ativismo. (grifos nossos) (FREIRE, 1997, p. 24).

Compreender o embate teórico sobre o estágio passa, certamente, por uma reflexão crítica sobre a prática, tal como indica Freire na epígrafe anterior. Parece-nos que, de fato, o segundo desafio é fazer com que os alunos e professores pudessem compreender as dificuldades que vêm sendo apontadas pelos diferentes autores (GATTI, 2000; KENSKI, 2001; PICONEZ, 2001; PIMENTA; LIMA, 2004; BARREIRO; GEBRAN, 2006; PIMENTA, 2006; GOMES, 2011), especialmente quanto à forma inadequada de como o estágio tem sido tratado na formação inicial.

Nesta direção, Piconez (2001) destaca, por exemplo, que as orientações do estágio

têm sido dirigidas em função de atividades programadas a priori, sem que tenham surgido das discussões entre educador-educando, no cotidiano da sala de aula, da escola. (p.17).

E, assim, há um distanciamento entre a teoria e a prática que não possibilita reflexões que possam dar suporte ao trabalho docente no cotidiano escolar.

Outra questão enunciada pela autora é a própria desvalorização do estágio pelos 
"agentes pedagógicos” e alunos envolvidos na formação, que não atribuem "valor e significado aos Estágios Supervisionados, considerando-os, muitas vezes, simples cumprimento de horas formais exigidas pela legislação" (PICONEZ, 2001, p.20).

Além disso, Kenski (2001) aponta para outras dificuldades em relação à prática dos estágios: $1^{\circ}$ ser desvinculado das atividades praticadas pelos alunos durante o curso; $2^{\circ}$ a falta de clareza do professor-supervisor na condução dos estágios, para uma adequada formação do "futuro" professor; $3^{\circ}$ as propostas de estágio são fundamentadas em "atividades esparsas", quando seria imprescindível a elaboração de um "projeto de preferência em conjunto, inclusive com o professor da escola de estagiário” (p. 40) para dar sentido ao campo do estágio.

Quando se aponta para algumas proposições para o estágio que o tornariam significativo, Fazenda (2001) acentua que se deve pensar no estágio de forma integrada com as outras disciplinas do curso a que está atrelado. Ou seja, "pensar num projeto coletivo maior para a formação do educador" (p. 56). Outra proposição, enfatizada por vários autores como Fazenda (2001), Kenski (2001), Piconez (2001), Pimenta e Lima (2004), Barreiro e Gebran (2006), Pimenta (2006) e Nakano e Ancassuerd (2011), é a de que o estágio se articule como prática de reflexão e possa esclarecer e aprofundar a relação dialética teoria-prática. Nesta direção, indicam que é fundamental a prática de pesquisa no desenvolvimento dos estágios, de forma a integrar o estagiário em situações reais vividas e nos processos decisórios dos diferentes agentes pedagógicos.

Ainda quanto aos estágios, Gatti (2000, p. 43) afirma que, apesar do redirecionamento dado, eles continuam apresentando "pontos críticos", pois sua programa- ção e controle são precários, sendo a simples observação de aula a atividade mais sistemática, a supervisão ineficaz, não havendo acompanhamento e nem orientação no local do estágio, entre outros aspectos. E quando a autora trata da relação teoria-prática, revela que "esta só se consolida com uma visão de contexto e com o delineamento de projetos de ação, os quais implicam uma espécie de filosofia de ação” (p. 56). Para Bourdieu (1997), esta filosofia de ação, chamada às vezes de disposicional, atualizaria as "potencialidades inscritas nos corpos dos agentes e na estrutura das situações nas quais eles atuam ou, mais precisamente, em sua relação” (p. 10).

A partir destes estudos, buscamos colocar o acento na relação teoria e prática no campo do estágio, com base na problemática política que o estrutura objetivamente, a que denominamos de dimensão político-normativa, e no que está sendo incorporado por estes estudantes: a dimensão epistemológico-metodológica. Tais dimensões serão analisadas mais adiante.

\section{- O $3^{\circ}$ desafio: o que propõe o PARFOR?}

É certo que a orientação da mudança (grifos nossos) depende do estado do sistema de possibilidades que são oferecidas pela história e que determinam o que é possível e impossível de fazer ou de pensar em um dado momento do tempo, em um campo determinado... (BOURDIEU, 1997, p. 63).

De fato, o terceiro desafio seria o de compreender quais princípios orientam o PARFOR (BRASIL, 2009), ao direcionar, de certo modo, "a mudança" e o "sistema de possibilidades", como afirma Bourdieu (1997, p. 63). É preciso saber, então, de que forma poderiam estar estruturando o campo 
do estágio e a relação teoria-prática frente às demais disposições legais que o regulamentam.

Dentre os princípios, mencionamos os que mais se aproximam à "estruturação" do campo do estágio, que estão descritos no art. $2^{\circ}$ do Decreto 6755/2009 (BRASIL, 2009), e se referem: à importância da relação teoria-prática (V); ao reconhecimento da "escola e demais instituições de educação básica como espaços necessários à formação inicial dos profissionais do magistério" (VI); à valorização de um projeto formativo "que reflita a especificidade da formação docente” e garanta a "sólida base teórica e interdisciplinar” (VII).

O Decreto 6755/09, em seu art. 12, também dispõe que o Ministério da Educação, ao implementar esta política, "deverá assegurar sua coerência com os processos de avaliação da educação básica e superior, (...) e as diretrizes curriculares nacionais dos cursos de licenciatura e pedagogia” (BRASIL, 2009, p. 7).

No que diz respeito ao curso de Pedagogia, campo da pesquisa, o Decreto $6755 / 09$, ao apontar para essas diretrizes, reforça o Par. CNE/CP n 5/2005 (BRASIL, 2005) e a Resolução CNE/CP n ${ }^{\circ}$ 1/2006 (BRASIL, 2006). Tal resolução define as Diretrizes Curriculares para o Curso de Pedagogia e estabelece uma nova concepção e organização curricular para o curso, com uma carga horária mínima de 3.200 horas, assim distribuídas: 2800 horas dedicadas às atividades formativas; 300 horas ao Estágio Supervisionado; e 100 horas de atividades teórico-práticas de aprofundamento em áreas específicas de interesse, por meio da iniciação científica, da extensão e da monitoria.

O que se nota é que o PARFOR segue às "disposições legais", que, como diria Bourdieu (1998c, p. 188), orientam, assim, “operações de crédito”, dando forma não só ao campo do estágio, mas a uma "filosofia de ação" e/ou "política curricular". Política esta, que, conforme Gimeno Sacristán (1998, p. 107), "prescreve certos mínimos e orientações curriculares", definindo, assim, novas concepções, organização e estruturação para os cursos de formação de professores. Mas quais seriam, de fato, as implicações destas regulações para a filosofia de ação e/ou política curricular que se quer ou se está interiorizando? É o que veremos depois.

\section{Contextualizando a pesquisa}

O estudo desenvolvido enquadra-se em um paradigma qualitativo de pesquisa, anunciado por Bogdan e Biklen (1994), entre outros, pois leva em conta a experiência vivida pelos atores sociais, buscando a "criação de significado" que dão aos fenômenos sociais. E, para entendermos melhor as escolhas metodológicas, recorremos, mais uma vez, a Bourdieu (1997, 1998a, 1998b), quando nos mostra a importância do pensar relacional e/ou do relacionalismo metodológico, pois, segundo ele (1998c, p. 31), "o real é relacional e é preciso pensar relacionalmente”. (p. 28).

Nesta perspectiva de se "pensar relacionalmente", a pesquisa se desenvolveu em três etapas. A primeira envolveu a aplicação de um questionário trifacetado, aplicado a 43 professores-estudantes do curso de Pedagogia/PARFOR, e composto por questões de perfil, para explorar a inserção social, profissional e acadêmica; associação livre de palavras; e questões abertas. Na segun$d a$ etapa, foi realizado um grupo focal com oito destes estudantes, obtendo, como aponta Gatti (2005, p. 11), "perspectivas diferentes sobre uma mesma questão”. O que permitiu, também, “a compreensão partilhada por pessoas no dia-a-dia e dos modos pelos quais os 
indivíduos são influenciados pelos outros” (p.11). Estabelecemos, então, algumas estratégias de aproximação entre os participantes de modo a deixá-los à vontade para expressar suas ideias, conflitos e reflexões a respeito, principalmente, da relação teoria-prática, e como ela vinha sendo tratada na Pedagogia/PARFOR. E, na terceira etapa, foram entrevistados três destes sujeitos, a fim de aprofundar os conhecimentos anteriores no contexto de formação e de trabalho, de modo a vislumbrar se estava havendo inovações na prática profissional.

Quanto aos 43 sujeitos pesquisados, foi possível identificar, em relação à função exercida, que: 8 (18,6\%) são pajens; 21 $(51,2 \%)$ atendentes de educação; e os demais: coordenador, professor de ensino fundamental e educação infantil, e professor de ensino médio. Dos estudantes, com funções diversas, um declarou atuar como professor de Português; outro, de História, Geografia e Sociologia; um terceiro, professor polivalente, que atua com crianças de 3 a 10 anos; um quarto expôs funções similares a de um auxiliar de secretaria; e um quinto, funções de gestor escolar. Todos se enquadram no início da profissão, pois apresentam de 01 a 03 anos nas funções mencionadas. Apenas um pertence ao gênero masculino.

A faixa etária varia entre 24 e 41 anos, com: $35(81,4 \%)$ alunos apresentando idades entre 31 a 41 anos; 22 (51,2\%) são casados ou mantêm união estável, oito $(18,6 \%)$ são separados e um é viúvo. A carga horária semanal de trabalho varia entre 30 e 50 horas. Dois $(4,6 \%)$ sujeitos informaram trabalhar 50 horas; seis (14\%), 40 horas; e 25 (58,1\%), 30 horas por semana.

A maioria afirma que o PARFOR oferece uma grande oportunidade de profissionalização, mas, ao mesmo tempo, muitos indicam que enfrentam dificuldades, como: número de horas trabalhadas; deslocamento; falta de compreensão e colaboração dos gestores de suas respectivas escolas; não reconhecimento da formação da Pedagogia/ PARFOR pela própria escola. Dentre as expectativas assinaladas, esperam conseguir, a partir deste curso, "superar os desafios da profissão por meio do conhecimento teórico-prático a ser adquirido durante o curso" (S2, S7, S12); "alcançar novos cargos como profissionais da educação" (S14, S32); "motivar os alunos com novas técnicas e/ou estratégias” (S5, S11, S28, S43).

E quanto à relação teoria e prática, os dados do questionário apontaram que cinco sujeitos $(11,6 \%)$ mencionaram o desejo por um direcionamento teórico ou prático do curso: "que ele me dê embasamento teórico" (S42); "aperfeiçoamento da prática pedagógica” (S25); "expectativas que o curso se mostre mais próximo da nossa realidade profissional, pois o acho muito teórico" (S40); "realmente a questão teórica, pois a prática nós já temos” (S32); “juntar a teoria à prática docente" (S37). Os dados indicam que os sujeitos revelam certo distanciamento entre teoria e prática.

Como a ideia era a de explorar um pouco mais a relação teoria-prática no campo do estágio, tendo em vista as implicações do PARFOR na formação destes professores-estudantes em início da profissão, os dados obtidos por meio do grupo focal e das entrevistas, a partir da análise de conteúdo (BARDIN, 2007) e da fundamentação bourdiana e freireana anteriormente explicitada, possibilitaram considerar duas dimensões de análise: a político-normativa e a epistemológico-metodológica, descritas a seguir. 


\section{- $1^{\text {a }}$ dimensão: político-normativa}

"Quando foi solicitado para conhecer a legislação sobre o estágio, assim como as normas para fazermos estágio em nossas escolas e/ou de nossos colegas, fiquei um pouco cansada, achando que seria algo muito pesado e sem interesse. Mas depois é que fui percebendo que era importante conhecermos para poder fazer a crítica e compreender o que estávamos implementando em nossas escolas e o que deveríamos estar fazendo, especialmente, em relação ao nosso PPP.” (S1, Entrevista)

Antes de descrever esta dimensão, é preciso destacar a compreensão que temos em relação às "disposições legais" e às reformas que elas pretendem "instituir"; assim como é preciso saber o que pensam os professores-estudantes a respeito. Tomando as palavras de Bourdieu (1996, p. 112), seria preciso "apreender o que é instituído". Mas mais do que isso: tomar consciência, como diria Freire (1997, p. 59), de nossa presença no mundo:

(...) que não se faz no isolamento, isenta da influência das forças sociais, que não se compreende fora da tensão entre o que herdo geneticamente e o que herdo social, cultural e historicamente.

Ou seja, era necessário conhecer as “disposições legais" para "poder fazer a crítica e compreender o que estávamos implementando em nossas escolas e o que deveríamos estar fazendo, especialmente, em relação ao nosso PPP”, tal como afirma a professora (S15). Mas como conscientizar estes professores-estudantes sobre as "disposições legais” que, muitas vezes, ficam no nível das "reformas"?

E, nesta direção, concordamos com Canário (2005), quando afirma que as “disposições legais” mostram que a lógica da reforma é diferente da lógica da inovação, e, por isso, é muito difícil instituir transformações. Segundo este autor, há, pelo menos, dois problemas a serem enfrentados neste caso. O primeiro é "o da passagem do nível da reforma para o nível da produção instituinte de inovações nas escolas" (p. 95). O segundo é "o da passagem do terreno experimental para a generalização ao conjunto das escolas”, pois "a reforma não produz mudanças reais, mas apenas potenciais, ou seja, normativos e protótipos de inovação”.

Estamos de acordo, ainda, com Canário (1994, p. 49), ao enunciar que a inovação é o "princípio estratégico de pensar globalmente e agir localmente". Desse entendimento, decorrem, pelo menos, três questões que nos instigaram durante a pesquisa: a filosofia de ação e/ou política curricular, enunciada pela legislação, que ampara o estágio e o PARFOR, surtiu efeitos na "cultura interiorizada do estágio”? Como o campo do estágio foi pensado pela instituição formadora? E como os professores-estudantes, no início de carreira, estavam incorporando estas "disposições legais” em suas práticas?

Para responder a estas perguntas, é possível afirmar, por meio do projeto pedagógico do curso (PPC) da instituição pesquisada, que foram seguidas e compreendidas por estes professores-estudantes as Diretrizes Curriculares Nacionais da Pedagogia (BRASIL, 2006), assim como outros dispositivos legais, entre eles, o Referencial Curricular Nacional para a Educação Infantil (BRASIL, 1998a) e as Diretrizes Curriculares Nacionais para o Ensino Fundamental (BRASIL, 1998b, 1998c). Toda esta legislação foi analisada junto a estes sujeitos, orientando a eles que observassem se os projetos pedagógicos das escolas "cumpriam" estes dispositivos legais; e procurando conscientizá-los, segundo Freire (1997), a respeito das implicações das políticas curriculares nas práticas. E são estes alguns dos depoimentos: 
"Foi interessante quando a professora pediu para observar a realidade, mas com outros olhos. Achei que não precisaria fazer o estágio, mas este modo de registrar, partindo do projeto da escola, tendo que ver, inclusive, se as leis estavam sendo citadas, foi diferente... Deu um pouco mais de vida ao que estávamos fazendo. Embora tenha tido muita dificuldade para acessar os documentos." (S7, Grupo Focal)

"Ainda não ficou claro, para mim, se a legislação apontada no projeto pedagógico estava sendo observada na prática. Entrevistei até a coordenação para saber se ela estava sabendo desta legislação $e$ se a escola estava cumprindo. Ela me respondeu que sim, mas que quando se está na prática, tentamos fazer o melhor (sic), e que todas estas reformas, de "cima para baixo”, não transformam nada, pois está no nosso compromisso com o outro a vontade de mudar." (S2, Entrevista)

"Senti, como professora de início de carreira, muitas dificuldades na formação da Pedagogia/PARFOR, em especial, no que toca ao entendimento de toda a legislação que sustenta a formação de professores. Mas o jeito com que foi trabalhada a legislação relacionada ao estágio supervisionado, de forma a ver se ela era compreendida e implementada pela direção, coordenação e corpo docente, fez com que me envolvesse mais com o desenvolvimento do PPP da escola e tomasse consciência da importância do estágio para a formação do professor e/ou da professora." (S3, Entrevista)

Neste sentido, mais do que verificar o "dever-ser" da legislação, os estudantes compreenderam esta relação do que estava sendo aprendido no contexto de formação com aquilo que vivenciavam na prática, por meio de outra leitura da realidade. Daí, como afirma Freire (1997, p. 31), era fundamental que estes estudantes pudessem compreender que "conhecer o conhecimento existente" é tão fundamental "quanto saber que estamos abertos e aptos à produção de conhecimento não existente”. Ou seja, eles estavam assumindo o estágio como campo de conhecimento, conforme apontam Pimenta e Lima (2004, p. 29), de modo a "atribuir-lhe um estatuto epistemológico que supere sua tradicional redução à atividade instrumental”. Talvez, uma "pitada" de inovação tenha sido dada neste "caldeirão" do PARFOR.

\section{- 2 dimensão: epistemológico- metodológica}

\begin{abstract}
"Neste primeiro ano de PARFOR, pude sentir o quanto aprendi e o quanto me cobrei para ser melhor no espaço da escola onde trabalho. O estágio contribui muito, porque pude olhar de forma diferente $o$ trabalho que faço com minhas crianças, tanto no conteúdo que desejo passar a elas, quanto nos modos de fazer isso. Penso que tem a ver com a tal articulação teoria e prática..." (S1 - Entrevista)
\end{abstract}

O curso de Pedagogia/PARFOR tem como proposta de estágio introduzir uma nova postura epistemológica e metodológica, tratando-o como campo de conhecimento, entendendo que o momento fundante é a relação teoria e prática, que possibilita, por exemplo, a intervenção na realidade, conforme Pimenta e Lima (2004). Ou seja, é imprescindível tratar o estágio como pesquisa na e para a realidade pesquisada, e como “espaço de aprendizagens e saberes”, segundo indicam Barreiro e Gebran (2006, p. 87). O que seria um exercício de reflexão sobre o sentido/significado de como o estágio pode estar mudando o "olhar" sobre a prática, tal como indica a professora da epígrafe anterior.

A partir disso, foram definidas três etapas para desenvolver o estágio dentro 
dessas concepções. Na primeira, foi introduzida a proposta, que era valorizar o olhar de pesquisador a partir da questão: "o que posso observar no espaço que atuo para ser registrado e posteriormente socializado?”. Definiram-se, a seguir, os roteiros por instituição, para tentar caracterizá-las, pois se trata de espaços bem diferenciados.

Na segunda etapa, foram construídos instrumentos de pesquisa - roteiros de entrevistas -, que deveriam ser realizadas junto a um gestor e a um profissional que atuasse com as crianças. Estes instrumentos também foram socializados (e problematizados) com a orientadora do estágio e os demais colegas. A última etapa foi a constituição de um relatório descritivo e analítico, contendo: a) contextualização do campo da pesquisa; b) perfil dos sujeitos pesquisados; c) relatos dos episódios de formação, contendo situações de trabalho e/ou práticas de ensino/aprendizagem significativas; d) reflexões temáticas sobre o que e como foi observado, que foram discutidas na instituição formadora. Dentre alguns depoimentos sobre o significado destas reflexões temáticas, citamos os que se seguem:

\begin{abstract}
"A compreensão do que e do como estava sendo ensinado e/ou aprendido o conteúdo (sic), seja ele ligado à alfabetização da língua portuguesa, da matemática, $e$ o enfrentamento das diferentes situações didáticas, vivenciadas por alunos e professores, contribuíram muito com minha formação. E é por isso que considero que o estágio é uma das formas legítimas de entender a relação teoria e prática, não é mesmo?" (S2 Entrevista)
\end{abstract}

"Aprendi que, além de observar os conteúdos desenvolvidos, estava também direcionando o meu olhar sobre a forma didática com que esta situação se desenvolvia por parte do professor. Mas o que me chamou a atenção foi perceber que 0 nosso aluno também nos ensina muito.
Foi estranho, à primeira vista, mas muito significativo apreender estas relações: entre o que se quer transmitir e o que, de fato, se aprende e/ou se apreende..." (S3 - Entrevista)

"Eu não olhava a escola e nem mesmo a sala de aula desta forma, e me surpreendo a cada dia. Foi importante dar um novo significado à teoria e à prática que vivencio ou àquela que observo e/ou participo." (S5 - Grupo Focal)

Estas reflexões esclareceram, segundo Gimeno Sacristán (1999, p. 19), que a relação teoria e prática "constitui um esforço para obter uma teoria explicativa do como, do porquê e do para que da prática educativa”. O estágio seria, então, um meio, diria Bourdieu (1998c, p. 118), de "explicar mais completamente a realidade, logo, de compreender e de prever mais exatamente as potencialidades que ela encerra ou, mais precisamente, as possibilidades que ela oferece às diferentes pretensões subjetivistas”. Mas o mais importante (e esta foi a concepção de estágio que perpassou a Pedagogia/PARFOR) segue o pensamento de Freire (1997), que diz: "o fundamental é a minha decisão ético-política, minha vontade nada piegas de intervir no mundo" (p. 155).

\section{Ainda mais algumas considerações: das implicações do PARFOR}

\footnotetext{
"Apesar de tantas dificuldades, estamos, com certeza, aprendendo a fazer a releitura da realidade, com outro olhar." (S8 - Grupo Focal)

O importante, não resta dúvida, é não pararmos satisfeitos ao nível das intuições, mas submetê-las à análise metodicamente rigorosa de nossa curiosidade epistemológica. (FREIRE, 1997, p. 51).
} 
Apresentamos, neste momento, uma reflexão sobre os depoimentos dos professores-estudantes a respeito das implicações do PARFOR no campo do estágio em relação ao contexto de trabalho e às práticas profissionais. Tais implicações, entendidas aqui como desafios a serem enfrentados e/ou proposições, poderiam ser consideradas como resultados de pesquisa:

$1^{\circ}$ No campo do estágio - os sujeitos apontam como desafios a serem superados no contexto de formação: a) a não integração do estágio com as demais disciplinas do currículo de formação de professores; b) a falta de articulação entre a instituição formadora e as escolas-campo; c) a desvalorização do estágio nos cursos de formação e para as escolas. E quanto às proposições, anunciam: a) considerar o estágio como campo de conhecimento; b) assumir uma postura de pesquisador (a) ao vivenciá-lo; c) entender que a relação teoria-prática é essencial para fortalecer o campo do estágio;

$2^{\circ}$ No contexto de trabalho: os depoimentos desvelam os seguintes desafios, que se colocam, de certa forma, como proposições: a) reafirmar a existência de um projeto de estágio, que seja planejado e avaliado pela instituição formadora e pelas escolas-campo; b) desenvolver uma postura metodológica e epistemológica do estágio de forma a avaliar propostas curriculares, que estão sendo realizadas na escola, ressignificando seus códigos e procedimentos, a fim de contribuir para a produção de conhecimentos; c) conscientizar coordenadores, professores e alunos da importância de se vivenciar o estágio como projeto de formação, que possibilite intervir e gerar inovações na escola.

$3^{\circ}$ Nas práticas profissionais: foram considerados como desafios: a) as "disposições legais”, que se colocam como "formas de regulação” e, que, ao normatizá- -las, podem, por vezes, cercear a realidade; b) desenvolver uma postura metodológica, a fim de ressignificar o estágio e a própria profissão docente. E como proposições (que também são desafios): a) identificar os problemas-chave relativos às situações de sala de aula, a fim de intervir com maior conscientização na "tradução pedagógica" dos conteúdos curriculares; e b) pensar na atividade docente, como valorização do método e organização do trabalho, tendo como pressupostos a transmissão e/ou a co-construção de conhecimento com base no diálogo entre a teoria e a prática.

Estes desafios e/ou proposições postos nos três campos, diria Bourdieu (2008), põem "em jogo diversos princípios de diferenciação” (p. 31) e, por vezes, anunciam, como no caso das proposições, alguns "princípios geradores de práticas distintas e distintivas” ou o que o autor denomina como habitus. Trata-se, aqui, de um corpo de problemas da profissão, dignos de serem discutidos nos programas de formação e/ou em outros espaços formativos para que novas práticas possam ser vivenciadas. E tudo isso implica o aprender, que, para Freire (1997, p. 77), é "construir, reconstruir, constatar para mudar (grifos do autor), o que não se faz sem abertura ao risco e à aventura do espírito".

De modo geral, estes resultados de pesquisa poderiam contribuir para uma reformulação da formação inicial, em especial, daquela voltada para professores em exercício e para aqueles que estão em seus primeiros anos de profissão. Contudo, para isso, seria preciso alinhavar o contexto de formação com o da prática, como já mencionamos, considerando a vivência destes sujeitos e das experiências apresentadas e buscando consolidar estratégias formativas que fossem programadas e acompanhadas. Estratégias que pudessem ser vivenciadas não só no campo do estágio, mas, sobretudo, 
no contexto do trabalho e das práticas profissionais, de modo a ressignificar a relação teoria e prática por parte destes professores iniciantes, dando-lhes, também, uma maior confiança para desempenhar a profissão, mobilizar intenções e ações, tanto para compreender a complexidade da Escola e da sala de aula, quanto para refletir sobre seus desafios e intervir em sua realidade.

Em síntese: as implicações do PARFOR, reveladas pelos professores-estudantes, reforçam que eles estão "aprendendo a fazer a releitura da realidade, com outro olhar”. Daí a importância de se considerar, aqui, o pensamento de Paulo Freire (1997, p. 51), quando afirma que não basta "pararmos satisfeitos ao nível das intuições”, mas é preciso "submetê-las à análise metodicamente rigorosa de nossa curiosidade epistemológica”. O que comprova, mais uma vez, as palavras de Bourdieu (1994, p. 7), registradas na epígrafe inicial e que aqui reforçamos: "a crítica epistemológica não se dá sem uma crítica social”.

\section{Referências}

ABDALLA, M. F. B. O senso prático de ser e estar na profissão. São Paulo: Cortez, 2006.

BARDIN, L. Análise de conteúdo. Lisboa: Edições 70, 2007.

BARREIRO, I. M.; GEBRAN, R. A. Prática de ensino e estágio supervisionado na formação de professores. São Paulo: Avercamp, 2006.

BOGDAN, R. BIKLEN, S.K. Investigação qualitativa em educação. Porto: Porto Editora, 1994.

BOURDIEU, P. Lições da aula: aula inaugural proferida no Collége de France. 2. ed. São Paulo: Ática, 1994.
BOURDIEU, P. A economia das trocas linguísticas. São Paulo: Editora Universidade de São Paulo, 1996.

Razões práticas: sobre a teoria da ação. Campinas: Papirus, 1997.

. A economia das trocas simbólicas. 5. ed. São Paulo: Perspectiva, 1998a.

O diploma e o cargo: relações entre o sistema de produção e o sistema de reprodução. NOGUEIRA, M.A.; CATANI, A. (Orgs.). Escritos de educação. Petrópolis: Vozes, 1998b, p. 127-144.

O poder simbólico. 2. ed. Rio de Janeiro: Bertrand Brasil, 1998c.

Capital cultural, escuela y espacio social. 2. ed. Buenos Aires: Siglo XXI Editores Argentina, 2008.

BRASIL. Ministério da Educação e do Desporto. Conselho Nacional de Educação. Secretaria de Educação Fundamental. Referencial Curricular Nacional para a Ed. Infantil. Brasília: MEC/SEF, 1998a.

Ministério da Educação e do Desporto. Conselho Nacional de Educação. Câmara de Educação Básica. Parecer CEB n. 4/98. Diretrizes Curriculares Nacionais para o Ensino Fundamental. Brasília: MEC/CNE, 1998b.

- Ministério da Educação e do Desporto. Conselho Nacional de Educação. Câmara de Educação Básica. Resolução n. 2, de $7 \mathrm{~d}$ abril de 1998. Institui as Diretrizes Curriculares Nacionais para o Ensino Fundamental. Diário Oficial da União. Brasília, 15 abr./98, 1998c.

Conselho Nacional de Educação. Parecer CNE/CP5/2005, de 13 de dezembro de 2005. Diretrizes Curriculares Nacionais para o Curso de Pedagogia. Brasília, 2005. 
BRASIL. Conselho Nacional de Educação. Resolução CNE/CP 1, de 15 de maio de 2006. Institui Diretrizes Curriculares para o Curso de Graduação em Pedagogia, licenciatura. Brasília, 2006.

Ministério da Educação/MEC. Decreto $\mathbf{n}^{\mathbf{0}}$ 6.755, de 29 de janeiro de 2009. Institui a Política Nacional de Formação de Profissionais do Magistério da Educação Básica, disciplina a atuação da Coordenação de Aperfeiçoamento de Pessoal de Nível Superior - Capes no fomento a programas de formação inicial e continuada, e dá outras providências. Brasília/DF: MEC, DOU, 30/01/2009.

CANÁRIO, Rui. Eco: um processo estratégico de mudança. In: D’ESPINEY, R.; CANÁRIO, R. Uma escola em mudança com a comunidade. Lisboa: I.I.E., 1994, p. 33-69.

O que é a escola? um "olhar" sociológico. Porto: Porto Editora, 2005.

CUNHA, M. I.; ZANCHET, B. M. B. A. A problemática dos professores iniciantes: tendência e prática investigativa no espaço universitário. Educação, Porto Alegre, v. 33, n. 3, p. 189-197, set./dez. 2010.

FAZENDA, I. C. A. O papel do estágio nos cursos de formação de professores. PICONEZ, S. C. B. (Org.). A prática de ensino e o estágio supervisionado. 7. ed. Campinas: Papirus, 2001, p. 53-62.

FREIRE, P. Pedagogia da autonomia: saberes necessários à prática educativa. São Paulo: Paz e Terra, 1997.

GATTI, B. A. Formação de professores e carreira: problemas e movimentos de renovação. Campinas: Autores Associados, 2000.

Grupo focal na pesquisa em ciências sociais e humanas. Brasília: Líber Livro Editora, 2005.
GIMENO SACRISTÁN, J. O currículo: uma reflexão sobre a prática. 3. ed. Porto Alegre: ArtMed, 1998.

Poderes instáveis em educação. Porto Alegre: ArtMed, 1999.

GOMES, M. O. Estágios na formação de professores: possibilidades formativas entre ensino, pesquisa e extensão. São Paulo: Edições Loyola, 2011.

KENSKI, V. M. A vivência escolar dos estagiários e a prática de pesquisa em estágios supervisionados. PICONEZ, S. C B. (Org.). A prática de ensino e o estágio supervisionado. 7. ed. Campinas: Papirus, 2001, p. 39-51.

MARCELO GARCÍA, C. Formação de professores: para uma mudança educativa. Porto: Porto Editora, 1999.

NAKANO, M.; ANCASSUERD, M. P. Estágio: memória e produção de conhecimento. GOMES, M. O. Estágios na formação de professores: possibilidades formativas entre ensino, pesquisa e extensão. São Paulo: Edições Loyola, 2011, p. 187222.

PICONEZ, S. C. B. A prática de ensino e o estágio supervisionado: a aproximação da realidade escolar e a prática da reflexão. . (Org.). A prática de ensino e o estágio supervisionado. 7. ed. Campinas: Papirus, 2001, p. 15-32.

PIMENTA, S. G.; LIMA, M. S. L. Estágio e docência. 2. ed. São Paulo: Cortez, 2004. (Coleção Docência em Formação)

PIMENTA, S. G. O estágio na formação de professores: unidade teoria e prática? 7. ed. São Paulo: Cortez Editora, 2006.

SILVA, M. C. M. O primeiro ano de docência: o choque com a realidade. ESTRELA, M. T. (Org.). Viver e construir a profissão docente. Porto: Porto Editora, 1997, p. 51-80. 
Das proposições do estágio supervisionado aos desafios da prática: a formação inicial de professores-estudantes...

VEENMAN, S. A. M. Perceived problems of beginning teachers. Review of Educational

Research, vol. 54, n. 2, p. 143-178, 1984.

Enviado em: 14/10/2012

Aceito em: 11/12/2012 